\title{
Psicodrama e acessibilidade: 0 olhar do psicodramatista com deficiência visual
}

\author{
Psychodrama and accessibility: the view of a \\ psychodramatist visually-impared
}

\section{Daniela Cardoso de Oliveira' ${ }^{1}$ (]) Gabriela Pereira Vidal ${ }^{2}$ (1) Amanda Castro 3 (1)}

\begin{abstract}
${ }^{1}$ Autora para correspondência. Viver Mais Psicologia (Tubarão). Santa Catarina, Brasil. danyolivie@gmail.com ${ }^{2}$ Viver Mais Psicologia (Tubarão), Centro Universitário Barriga Verde (Orleans). Santa Catarina, Brasil. gabrielavidaal@gmail.com 3Universidade Estácio de Sá, Universidade do Extremo Sul Catarinense, Viver Mais Psicologia (Tubarão). Santa Catarina, Brasil. amandacastrops@gmail.com
\end{abstract}

RESUMO | INTRODUÇÃO: É possível fazer psicodrama sem enxergar? Essa pergunta originou este aprofundamento de um relato das vivências de uma das autoras, estudante de psicologia, psicodramatista em formação e pessoa cega. OBJETIVOS: Apresenta-se, neste estudo, uma investigação teórica de cunho psicodramático, que discute o imagético versus simbólico no psicodrama e a espontaneidade como fator de inclusão, com o objetivo de debater a possibilidade de psicoterapeutas com deficiência visual serem diretores de psicodrama e as conservas culturais em relação à deficiência presentes no meio psicodramático. MÉTODOS: A metodologia utilizada foi a pesquisa de narrativa autobiográfica, a qual permite que o ponto de partida para a análise seja a percepção subjetiva do próprio sujeito, e a compreensão do relato foi viabilizada por meio de análise de conteúdo. RESULTADOS: Desse modo, a discussão dos dados pretendeu elucidar algumas conservas culturais no campo das psicoterapias, sobretudo psicodramáticas, bem como as possibilidades de desconstruí-las para viabilizar um psicodrama acessível e possível aos diretores com deficiência visual. CONCLUSÃO: Conclui-se pela emergência de pesquisas e ações que enfoquem as pessoas com deficiência para além da habilitação e reabilitação, ampliando-se o campo das psicoterapias para uma compreensão destes como sujeitos ativos nos fazeres psicológicos.

PALAVRAS-CHAVE: Psicodrama. Psicoterapia. Acessibilidade. Deficiência visual.

\begin{abstract}
INTRODUCTION: Is it possible to do psychodrama without seeing? This question originated this deepening of an account of the experiences of one of the authors, a psychology student, a psychodramatist in training, and a blind person. OBJECTIVES: In this study, a theoretical investigation of a psychodramatic nature is presented, which discusses the imaginary versus symbolic in psychodrama and spontaneity as an inclusion factor, to debate the possibility of psychotherapists with visual impairment being psychodrama directors and cultural preserves concerning the disability present in the psychodramatic environment. METHODS: The methodology used was the research of autobiographical narrative, which allows the starting point for the analysis to be the subjective perception of the subject himself, and the comprehension of the report was made possible through content analysis. RESULTS: In this way, the discussion of the data intended to elucidate some cultural preserves in the field of psychotherapies, especially psychodramatic ones, as well as the possibilities of deconstructing them to make an accessible and possible psychodrama for directors with visual impairments. CONCLUSION: It concludes by the emergence of research and actions that focus on people with disabilities beyond qualification and rehabilitation, expanding the field of psychotherapies to understand them as active subjects in psychological activities.
\end{abstract}

KEYWORDS: Psychodrama. Psychotherapy. Accessibility. Visually-impaired 


\section{Introdução}

A forma como as pessoas com deficiência foram encaradas ao longo da história vem se modificando de acordo com os valores sociais, morais, filosóficos, éticos e religiosos de cada época e cultura (Moises \& Stockmann, 2020). O século XXI, sobretudo a partir da Convenção Internacional sobre os Direitos das Pessoas com Deficiência da ONU, trouxe consigo um modelo social de deficiência, que, diferente do modelo anterior que percebia a deficiência como enfermidade médica, propõe que essas ocorrem na interação com as diversas barreiras sociais, as quais podem obstruir a participação desses indivíduos na sociedade em igualdade de condições com as demais pessoas (Decreto n. 6.949, 2009).

Apesar desses avanços, as pessoas com deficiência ainda são vistas socialmente ou como frágeis e incapazes, ou como corajosas e cheias de força de vontade, refletindo a proeminência de uma lógica capacitista que rege as relações sociais desses indivíduos. O capacitismo trata-se do modo que pessoas com deficiência denominam o preconceito por elas sofrido. Conforme descrito por Mello (2016), a partir de um padrão de normalidade corpórea, o capacitismo baseia-se na premissa da (in)capacidade, ou seja, no que pessoas com deficiência são capazes de ser ou fazer, negando reiteradamente suas possibilidades nas mais diversas esferas da vida social.

O Psicodrama, criado por Jacob Levy Moreno, é uma das abordagens de trabalho em psicoterapia e percebe o indivíduo dentro do seu meio, não como um ser isolado, mas como um ser em relação (RojasBermúdez, 2016). O homem, de acordo com Moreno, nasce espontâneo e criativo e ao longo de sua vida perde essas características. O criador do psicodrama pretendia que as sessões psicodramáticas fossem experiências existenciais e, ainda de acordo com RojasBermúdez (2016, p. 21): “diferentemente das psicoterapias puramente verbais, o psicodrama faz intervir, manifestamente, o corpo em suas variadas expressões e interações com outros corpos". Assim, no meio psicodramático, utiliza-se muito do corpo e, por esse motivo, muitos consideram o Psicodrama inacessível a pessoas com deficiência visual, acreditando que as apropriações de corpo e espaço ocorrem por via exclusivamente da visão.

Cabe ressaltar, no entanto, que o trabalho de Moreno, seja em sua perspectiva sociológica, educacional ou psicoterapêutica, esteve sempre fundamentado na tentativa de ajudar as pessoas na inclusão em suas relações. São vários os momentos nos quais Moreno trabalhou com a inclusão: acolhendo os pobres com a Religião do Encontro, incluindo as prostitutas de Viena, trabalhando com refugiados tiroleses durante a I Guerra Mundial e, posteriormente, com prisioneiros em Sing Sing, com meninas menores infratoras em Hudson e com psicóticos no seu hospital psiquiátrico em Beacon (Fonseca, 2018). Além disso, Fonseca (2018) destaca que a estabilidade emocional do indivíduo está relacionada ao seu status sociométrico grupal, de modo que os membros isolados e periféricos seriam mais suscetíveis a adoecer. Ou seja, falar de inclusão é também falar de saúde.

A despeito de toda a trajetória de Moreno e do reconhecimento de que o psicodrama tem como base o ser espontâneo, por vezes o estar diante de uma pessoa com deficiência ainda se configura como impossibilidade ou grande dificuldade de adaptação. A espontaneidade, no psicodrama, relaciona-se à prontidão do indivíduo para responder às situações de acordo com o que the seja apresentado, uma vez que esteja preparado para agir com liberdade (Moreno, 2016). É nesse sentido que este escrito foi baseado no relato de uma das autoras, em um momento de caos de sentimentos, para propor uma reflexão acerca da acessibilidade dentro do psicodrama e como se pode construí-la de forma espontânea e criativa.

\section{Método}

Este artigo trata-se de uma investigação teórica baseada em uma pesquisa autobiográfica, na qual, de acordo com Souza e Aliança (2018, p.566), "a subjetividade tem vez e voz, e esta última é justamente seu objeto de estudo. É a narrativa construída pelo sujeito, com ou sem intervenção direta do pesquisador, o material sobre o qual vai se debruçar." Assim, utiliza-se de uma narrativa construída pelo próprio pesquisador para a análise, um tipo de pesquisa que pode ser considerada, de acordo com Marques e Satriano, como "viável, válida e mais, como uma alternativa rica no estudo sobre o ser humano" (2017, p.383). Nas ciências humanas, a pesquisa autobiográfica ocupa um espaço recente, mas que se amplia cada vez mais, principalmente diante da necessidade de revelar quem são, quais suas perspectivas e de onde escrevem e pensam aqueles que são protagonistas 
na construção do conhecimento (Silveira, 2019). Diante disso, um dos obstáculos apontados por alguns autores é justamente a possibilidade de uma imparcialidade ou um autoengano diante da narrativa, algo que, neste estudo, tentou-se equilibrar com a escrita e análise conjunta com outras autoras, as quais garantiriam maior legitimidade dos resultados (Marques \& Satriano, 2017).

Assim, este artigo apresenta uma investigação teórica de cunho psicodramático baseada em um relato de experiência de Daniela Cardoso de Oliveira, na época graduanda em psicologia, psicodramatista em formação, de 27 anos, e com deficiência visual congênita. $O$ relato foi escrito em 01/02/2020, em um momento de caos de sentimentos, tais como indignação, tristeza, decepção, e raiva, frente a discursos capacitistas sobre o desempenho profissional em Psicodrama por pessoas com deficiência visual, e integra percepções subjetivas e descrições de práticas dos estágios supervisionados da graduação. Em relação ao contexto que originou a escrita, a autora da narrativa soube por meio de colegas com deficiência visual que alguns vinham vivenciando atitudes capacitistas no meio psicodramático, o que fez emergir essa temática alguns dias depois em um sociodrama ${ }^{1}$ como uma cena temida de rejeição em virtude de sua deficiência visual, contextualizando um momento disparador na escrita do relato analisado.

O relato de Daniela Cardoso de Oliveira (pesquisadora e participante) foi descrito, fundamentado e discutido sobre o olhar da teoria psicodramática e sua aplicação, buscando viabilizar respostas espontâneas que possibilitem novas percepções acerca da deficiência visual no psicodrama. Para isso, realizou-se uma análise de conteúdo, ou seja, inicialmente as autoras fizeram leituras repetidas do relato analisado, separadamente, destacando os aspectos que Ihes pareciam mais plenos de significado e posteriormente, em conjunto, escolheram os trechos que comporiam a análise e fizeram sua discussão teórica a partir das categorias que compõem os subtítulos do capítulo de discussão do presente estudo (Carlomagno \& Rocha, 2016). Os autores supracitados afirmam que é possível fazer a análise de conteúdo a partir de qualquer tipo de ato enunciativo, independentemente do meio pelo qual seja viabilizado, e acrescentam que: "A metodologia de análise de conteúdo se destina a classificar e categorizar qualquer tipo de conteúdo, reduzindo suas características a elementos-chave, de modo com que sejam comparáveis a uma série de outros elementos." (Carlomagno \& Rocha, 2016, p. 175). Além disso, a justificativa para utilização deste material se baseia no número de psicodramatistas formados ou em formação com deficiência visual, já que, de acordo com o conhecimento das autoras, não haveria uma amostra representativa para outros tipos de estudo, assim como boa parte das referências na análise é de autores que discutem outras temáticas de minorias sociais, em razão de ainda não haver literatura psicodramática aprofundada na temática dos Estudos sobre Deficiência.

\section{Discussão}

\section{O Psicodrama e as conservas Culturais da deficiência}

Alguns psicodramatistas desenvolveram estudos e discussões nos últimos anos acerca das deficiências físicas, sensoriais e intelectuais que, apesar de desatualizados, contribuem muito para nosso olhar a esse público (Auad \& Conceição, 2008; Monteiro, 2005). Entre esses, no entanto, nenhum estudo foi encontrado acerca de psicodramatistas com deficiências, proporcionando a esta discussão um conteúdo de alguma forma inédito. Para elucidar a questão, o trecho inicial do relato aqui analisado apresenta justamente a pergunta chave e a inquietação geradora desta análise: 
"É possível fazer psicodrama sem enxergar?" Essa pergunta, vinda de uma psicóloga também cega, me impactou muito mais do que gostaria de admitir: gerou uma indignação brutal, fez rolar algumas lágrimas de olhos não muito acostumados a chorar e acabou emergindo como cena temida durante o aquecimento para um sociodrama. A resposta, apesar de ser para mim muito clara, é difícil de expressar e embasar dentro do próprio psicodrama (Daniela Cardoso de Oliveira, 2020).

A ideia da impossibilidade advém, na teoria psicodramática, do que é conhecido como Conserva Cultural, a qual pode ser entendida como a cristalização do produto de uma ação criadora em algo que passará a integrar o acervo de uma sociedade, permitindo a esta preservar sua cultura, sua arte, sua língua, sua ciência e sua tecnologia (Menegazzo, Tomasini \& Zureti, 2019). Ou seja, a conserva cultural não é negativa em si mesma, porém se faz necessário evitar seu excesso em função do risco de poder sufocar a espontaneidade e a criatividade e, na ânsia de ter respostas para o desconhecido, deixar que as conservas transformem o ser humano em um robô previamente programado (Martín, 2019).

Essas conservas fazem com que diariamente o diferente precise lidar com o preconceito da sociedade. Bustos (2020) afirma que o próprio Moreno, criador da teoria, sempre foi atraído pela temática da discriminação, que aquilo que era considerado convencional ou consagrado socialmente o atraiu a pesquisar e buscar o entendimento das relações por outras perspectivas. Além disso, o autor fala da carência afetiva de Moreno e da sua dificuldade de pertença em alguns grupos sociais da época, assim como pode acontecer à pessoa com deficiência atualmente.

Ainda de acordo com Bustos (2020, p. 88), "o desconhecimento substituído pelo preconceito mata". Assim, o preconceito vem do desconhecimento, não compreensão ou ignorância de parte da sociedade. Dessa forma, a conserva cultural dos preconceitos talvez se origine do desconhecimento, mas quando esse desconhecimento evolui, passa a ser tão perigoso quanto uma arma social, que pode gerar uma série de consequências, inclusive a morte. Em escrita sobre racismo, feminicídio e outros, o autor ainda descreve: "em toda sociedade organizada existem representantes dos valores arcaicos. Nós os vemos diariamente dizendo coisas que pertencem a séculos atrás" (p. 89). Ou seja, vemos as pessoas perpetuando esse mesmo desconhecimento que gera o preconceito.

A repetição nem sempre é boa ou saudável, de modo que a discussão aqui proposta abre a possibilidade de um novo olhar para o psicodramatista com deficiência e o real significado dessa na sua prática, buscando trabalhar a conserva cultural da deficiência, ou seja, a repetição ou insistência em um padrão para o seu descongelamento, a fim de propiciar o desenvolvimento espontâneo e criativo desta discussão (Merengué, 2009). Nery (2020) explica que a vida social é repleta de experiências de poder, como as conservas culturais de grupos dominantes e dominados, e por isso os indivíduos aprendem a exercer e viver nesse padrão, de modo que essa modalidade vincular continue nos papéis sociais desempenhados e se perpetue socialmente. Assim, a autora (2020, p.116) defende que "os papéis históricos e a modalidade vincular de poder nos trazem a necessidade da (re) vivência criativa ou do reaprendizado do exercício do poder em nossos diversos campos de atuação". Dessa forma, busca-se a elucidação das conservas culturais sobre o psicodramatista com deficiência visual, para a percepção e análise do quanto elas se fazem válidas ou não em sua prática.

\section{O psicodramatista com deficiência visual}

Quem é o psicólogo ou psicoterapeuta clínico? Em estudo recente sobre as representações sociais de psicólogos, uma representação em destaque é a caracterização da profissão do psicólogo como "assistencialista", ou seja, de uma ajuda incondicional ao outro (Nóbrega, 2017). A autora destaca que "o trabalho do psicólogo se desenvolve como uma organização de peças, isto é, como quem monta um quebra-cabeça, esse profissional busca a solução para o problema" (p.397). Para além disso, o estudo destaca ainda o compromisso social, o amor pela profissão e a ética como representações importantes (Nóbrega, 2017). Nesse sentido, questionamo-nos se essas representações mudariam para as pessoas com deficiência visual. 
Eu sou cega. E psicodramatista. Sim, eu sei, não sou sequer psicóloga formalmente, mas sou psicodramatista porque sei que faço do psicodrama minha verdade pessoal e profissional. O diploma da graduação, a monografia e o certificado da FEBRAP2 são meras formalidades que afirmam aquilo que,

obviamente, vai se construindo ao longo de um processo que começa muito antes. Sou psicodramatista porque esse processo já está em andamento para mim

(Daniela Cardoso de Oliveira, 2020).

O que define o papel de psicodramatista é mais um questionamento que aquece esta discussão. Talvez o que possa auxiliar nesse caminho seja o próprio conceito de Psicodrama, definido por Rojas-Bermúdez (2016, p.21) como: "em princípio, um processo de ação e interação [...] faz intervir, manifestamente, o corpo em suas variadas expressões e interações com outros corpos", o que ocorre no aqui e agora, e, através da dramatização, busca trabalhar as verdades do indivíduo. Assim, é possível dizer que independente das formalidades acadêmicas, o psicodramatista é aquele que conduz a ação dramática através do método psicodramático, auxiliando o sujeito na busca por suas verdades.

Iniciei meu contato com o psicodrama como parte de uma liga acadêmica que trabalhava muito com teatro espontâneo. Adaptamos tudo quanto foi necessário nos jogos dramáticos para que eu pudesse participar

(falando assim parece muito, mas as modificações foram ínfimas) e construímos as mais diversas $e$ hilárias cenas que se possa imaginar. Quando esse grupo foi aprofundando nas práticas socionômicas e os participantes foram se experimentando no role-play de diretores, realizei minha primeira direção da vida: um sociodrama, com a temática "como lidar com as diferenças", cujo aquecimento envolvia, pasmem(!), escultura corporal. Nesse dia dei os primeiros passos dentro do que eu faria muitas vezes ainda: pedir descrições de imagens e usar essas informações dentro do processo terapêutico (Daniela Cardoso de Oliveira, 2020).
Os Estudos sobre Deficiência propõem uma compreensão desta como apenas mais um aspecto que compõe a diversidade humana. Nesse sentido, compreende-se a falta de inclusão menos como uma característica individual e mais como despreparo e escassez de atitudes sociais, de modo que é papel de cada indivíduo, com ou sem deficiência, incorporar a acessibilidade e a inclusão em seus atos e decisões para se alcançar uma sociedade mais livre e equânime (Amaral, 2019; Santos, 2016). Ainda assim, embora muito se fale no direito à participação social em igualdade de condições, percebe-se haver bastante dificuldade de adequação dos espaços e atitudes de modo a promover a inclusão das pessoas com deficiência.

Em relação a essas dificuldades, o Psicodrama propõe um conceito essencial para sua discussão: a espontaneidade, que consiste na capacidade do sujeito de adaptar-se de maneira adequada a novas situações que possam surgir em sua vida (Rojas-Bermúdez, 2016; Moreno, 2016). Assim, ser espontâneo é reagir de maneira adequada às situações, às relações e a tudo que o cerca, inclusive à deficiência. Neste relato, a autora e o grupo agiram de forma espontânea diante de uma nova situação. Ao dirigir o sociodrama, foi possível perceber a necessidade de adequações, como as descrições de imagens, e sinalizar isso ao grupo, que também age espontaneamente ao se adequar e descrevê-las, possibilitando a construção de imagens simbólicas na imaginação da diretora.

O tempo foi passando e pulei para o estágio clínico. Queria muito ser essa mulher incrivel que todo mundo vê em mim, mas sou só mais uma estudante de psicologia e, como todo ser humano pré-psicólogo, estava morrendo de medo de não dar conta da clínica. Sendo cega, então? Não vou fingir que eu mesma nunca tive minhas dúvidas. Agora seria real. Não com meus colegas de grupo, mas com pacientes reais. Sendo para valer, eu não podia errar (Daniela Cardoso de Oliveira, 2020).

2 Federação Brasileira de Psicodrama. 
Moreno (2016, p.27) descreveu que "o papel é a forma de funcionamento que o indivíduo assume no momento específico em que reage a uma situação específica na qual outras pessoas ou objetos estão envolvidos". Martín (2019) ressalta que o desempenho de um papel social está sempre em relação com outras coisas e pessoas, de modo que o Eu de um indivíduo é sempre um Eu de papéis. Assim, este papel de psicoterapeuta/psicodramatista foi constituído em intersecção com diversos outros, entre eles o de pessoa com deficiência, através das vivências sociais da autora, nas quais pode ter aprendido e reforçado a conserva cultural de que não pode errar.

Essas conservas, que podem dizer respeito inclusive à visão histórica da deficiência, por mais que não façam parte da verdade pessoal do indivíduo, podem criar a ideia de forma inconsciente de que precisa provar isso a sociedade, na lógica de que qualquer erro que cometa pode reforçar a visão de que não seria capaz de desempenhar o papel. Para além disso, a primeira etapa no desenvolvimento de qualquer papel (role-taking) ocorre por meio da identificação com um modelo prévio. A falta de representatividade no Psicodrama e, consequentemente, a tomada do papel a partir de psicodramatistas videntes, portanto, requer que a pessoa com deficiência visual construa seu modo próprio de fazer psicodrama a partir de modelos que não vivenciam a ausência da visão, o que, ainda que não lhe seja imposto diretamente, pode reforçar sua insegurança de não ser capaz de corresponder ao desempenho adequado do papel.

\section{O desenvolvimento da espontaneidade no papel}

Eu não fui uma estagiária incrivelmente, indescritivelmente e incomparavelmente magnífica, tive lá minha cota de expectativas frustradas, mas consegui desenvolver o papel de psicoterapeuta dentro do que as minhas possibilidades humanas me permitiam naquele momento. Isso não teve absolutamente nada a ver com a deficiência visual: todos os meus conflitos foram puramente emocionais, meramente humanos e comuns [...] Desafiei-me de todas as formas possiveis, com todas as faixas etárias possíveis e até banquei, junto com uma amiga, a criação do primeiro grupo psicoterapêutico das clínicas integradas da

universidade na qual estudo. Não vou dizer que nunca rolou um chutezinho (sic) numa almofada aqui e uma quase destruiçãozinha de cenário ali. Apesar da minha orgulhosamente maravilhosa orientação espacial, acidentes acontecem - e são mais passíveis de acontecer se você for cega -, mas a gente dá uma risadinha, cuida para não desaquecer o paciente/grupo e toca em frente (Daniela Cardoso de Oliveira, 2020).

Cabe ressaltar que para desenvolver novas respostas o indivíduo se utiliza da espontaneidade como um catalisador, algo intermediário e que desencadeia a criatividade (Martín, 2019). Reagir de forma espontânea e criativa é libertar-se das conservas culturais, uma identificação em um novo patamar (Fonseca, 2018). “Espontaneidade-criatividade: trata-se da capacidade de vivenciar novidade, da renovação, de adicionar algo, ao invés da mesmice de sempre." (Moreno, Z., Blomkvist, \& Rutzel, 2001, p. 36). Desse modo, através da espontaneidade e criatividade, a autora pode criar formas de manejo das direções de modo que o visual/imagético não se configure como um embotador da sua espontaneidade. Além disso, assim como qualquer outro sujeito que se proponha a este papel, o psicoterapeuta com deficiência se depara com diversos desafios também frente a outras questões no seu processo de formação, para os quais precisará buscar por respostas espontâneas e criativas que viabilizem seu desenvolvimento acadêmico-profissional.

No meio dessa história toda iniciei a formação em psicodrama. Foi nas aulas da formação, sobretudo, que o psicodrama se tornou o que é hoje para mim: "O caminho, a verdade e a vida", como citava em tom de brincadeira hoje à tarde. Foi ali, naquele meio tão específico, formado por especialistas naquilo que eu queria me dedicar, que encontrei o acolhimento e o apoio necessários para me lançar em tudo que veio depois. Jamais ouvi perguntas sobre como eu conseguiria fazer isso ou aquilo. Assumimos a verdade de que eu conseguiria e passamos a trabalhar no como eu conseguiria. E esse como é tão simples, tão simples, que me dói imensamente ter que estar aqui falando sobre ele (Daniela Cardoso de Oliveira, 2020).

Essa cocriação de um Psicodrama acessível só acontece pela existência da tele. Conforme Perazzo (2019), Moreno compreendia tele tanto como um fator, semelhante a espontaneidade, capaz de atuar em determinado momento em uma relação, responsável pela força de coesão ou estabilidade de um grupo, quanto como um canal de comunicação que leva a possibilidade do encontro. Assim, a tele foi responsável pela força, coesão e equilíbrio do grupo de formação da autora ao caminhar para um psicodrama 
acessível, já que em momento algum o grupo duvidou ou questionou essa possibilidade, apenas cocriou, de forma espontânea e criativa, aquilo que era necessidade de uma integrante e, através da tele, necessidade do grupo. A partir do momento que isso ocorre, é possível pensar na inclusão social de fato, aquela da utopia moreniana, de que possa haver uma inclusão de todos por todos que, por meio de relações télicas, passem a cocriar espaços de respeito mútuo às diferenças. Moreno ensina que a criança, ao nascer, é incluída em uma matriz de identidade, ou seja, uma rede relacional de variadas influências(genéticas, culturais, sociais, psicológicas etc.). Nessas situações, acrescenta, existem dois polos em jogo: o do que busca a inclusão e o que aceita, rejeita ou é indiferente a ela. Desse modo, a verdadeira inclusão ocorre apenas quando o indivíduo experimenta a reciprocidade relacional que se manifesta pela inversão de papéis, pela tele e pelo encontro (Fonseca, 2018). A respeito da inclusão de psicoterapeutas com deficiência, a autora destaca que:

Pouco se fala, dentro da própria psicologia, no atendimento às pessoas com deficiência para além da habilitação e reabilitação: seus dramas reais, seus desafios reais e suas possibilidades reais. Menos ainda se fala, na verdade ignora-se mesmo que exista, o terapeuta com deficiência. Isso gera, como na colega psicóloga cega lá do início deste relato, as dúvidas se podemos utilizar determinadas práticas (Daniela Cardoso de Oliveira, 2020).

Como destacado anteriormente, os estudos acerca de psicodrama e deficiência são voltados à pessoa como sujeito passivo. Aqui, no entanto, apresenta-se o sujeito ativo que, de forma espontânea, desenvolve seu papel de psicoterapeuta, como qualquer outro, por meio da tomada, jogo e criação de papéis. É importante evidenciar que esse papel é extremamente subjetivo, ou seja, único de cada um. Com isso, destaca-se que, embora esta discussão esteja centrada no relato vivencial da autora, ela não se configura como única possibilidade de intervenção do psicodramatista com deficiência visual, uma vez que cada indivíduo poderá e deverá construir sua forma de fazer Psicodrama.

O psicodrama, por seu caráter dinâmico e sua ilusão de ser puramente imagético, se apresenta quase sempre como uma impossibilidade. O psicodrama para pessoas com deficiência visual é possível. Eu faço. E não faço porque sou incrível, magnífica, um "exeeemplo de superação" (quem me conhece sabe que odeio esse termo). Faço porque me foi dada a oportunidade de fazer. Eu não sabia como seria, minha orientadora não sabia como seria, nenhum dos meus colegas ou professores sabia como seria. Nos permitimos descobrir. Porque, como me disse muito sabiamente alguém uma vez, incluir é nada mais do que ser espontâneo: a pessoa com deficiência se apresenta para nós como uma situação nova e, se nos orgulhamos de ser psicodramatistas, não podemos nos furtar de, diante dela, buscar por uma resposta adequada às suas necessidades (Daniela Cardoso de Oliveira, 2020).

De acordo com Bisol, Pegorini e Valentini (2017), as transformações nas formas de se compreender os padrões e as relações com as pessoas com deficiência, a partir da mudança de um modelo biomédico para um modelo social, contribuem para deflagrar possibilidades de novas expressões e novas lógicas, repensando as formas de inclusão desses sujeitos nos diferentes modelos e instituições. Nesse sentido, a emergência do surgimento de psicólogos com deficiência e, consequentemente, psicodramatistas com deficiência, desafia-nos a pensar como temos discutido ou não sobre inclusão em nosso meio, como podemos estar reforçando uma lógica capacitista e quais barreiras sociais, entendendo que estas também são conservas culturais, temos imposto a essas pessoas, impedindo relações télicas e espontâneas que possibilitem a sua plena participação nos espaços de discussões e fazeres psicológicos.

Assim, uma perspectiva trazida por Bustos (2020) para pensar a sexualidade nos consultórios e nas ciências da saúde, talvez caiba também ao contexto da pessoa com deficiência: o autor pontua acerca da naturalização do sofrimento das pessoas e de como os próprios preconceitos do profissional acabam incorporados nas práticas de saúde como naturais, de modo que os procedimentos de saúde também podem - e devem ser repensados e reformulados. Quando psicodramatistas deduzem que não podem se utilizar de determinada técnica porque há uma pessoa com deficiência visual em um grupo, por exemplo, adentra-se nesse espaço, no qual é tão natural a conserva cultural capacitista da inadequação do corpo deficiente, que já nem se tenta a inclusão e até se evita que ela seja vista como necessária. Assim, perpetua-se a discriminação, o preconceito e o sofrimento psíquico desses sujeitos, que acabam por evitar as psicoterapias por não se sentirem contemplados por seus processos de "cura". 
"O psicodrama não é visual, o psicodrama é simbólico". Essa frase, que uso muito e até gostaria que fosse minha, ouvi de uma professora muito querida, enquanto expressava, no meio de uma aula da formação, meus medos em encarar o estágio clínico da graduação. Dizia minha orientadora de estágio, muito antes de ser minha orientadora de qualquer coisa, que: "não vejo nenhuma técnica do psicodrama que tu não possas aplicar". Essas afirmações só se tornaram verdades para mim ao longo do processo, enquanto fui me experimentando e desafiando dentro do psicodrama. Para mim, é autoexplicativo: eu faço psicodrama, individual e grupal, em psicoterapia da relação, psicodrama interno e cena aberta (por que não?), tudo isso sem ver (não tenho escolha, gente!). Eu leio muito sobre psicodrama (eu te amo, Ágora ${ }^{3}$ ) e já tive a oportunidade de utilizar, dentro da minha pouca experiência, uma variedade de técnicas aplicando os principais métodos psicodramáticos (Daniela Cardoso de Oliveira, 2020).

Psicodramatistas costumam dizer que o Psicodrama trabalha muito com o visual e imagético. Mas, se assim é, quem não vê a imagem não pode fazer ou viver o psicodrama? A resposta a essa pergunta só pode ser afirmativa se desconsiderarmos um importante elemento psicodramático: a realidade suplementar. Trata-se de uma realidade subjetiva, o "como se" do psicodrama, na qual o real e o simbólico se encontram, desvelando possibilidades para além da realidade concreta objetiva (Moreno, Z., Blomkvist \& Rutzel, 2001). De certo modo, a pessoa com deficiência visual já simboliza o mundo mentalmente a partir do que recebe do ambiente externo, portanto, é possível dizer que o "como se" é quase um lugar comum da sua realidade, ou seja, todo o mundo visual se apresenta para ela como uma realidade suplementar. Dessa forma, simbolizar a imagem na realidade suplementar não se torna um "desafio" ao diretor cego ou com baixa visão, mas sim um caminho acessível e quase natural.

Em relação ao espelho, por exemplo, talvez uma das técnicas mais visuais do Psicodrama, a qual consiste em captar e representar com exatidão a postura, ações e verbalizações do paciente assim como se apresentam em determinado momento (Rojas-Bermúdez, 2016), o primeiro ímpeto para aqueles que veem, imbuídos das conservas acerca da pessoa com deficiência visual, poderia ser pensar na impossibilidade de sua aplicação por quem não enxerga. Afinal, como espelhar o que não se vê? Além da multiplicidade de aplicações dessa técnica, pedindo-se para o paciente ver a cena de fora e descrever o que vê e como se sente, por exemplo, o diretor com deficiência visual ainda pode, por meio da descrição da imagem, utilizá-la da maneira mais clássica e espelhar a imagem corporal do protagonista como fora por ele descrita.

Assim sendo, ao desenvolver possibilidades, a autora deste relato em alguns momentos pede descrições de imagens para que possa simbolizar a realidade objetiva do que ocorre no cenário psicodramático. Em muitos outros, no entanto, ao estar telicamente conectada com o paciente ou grupo, percebe não haver a necessidade dessas descrições, porque aquilo que ocorre com os participantes de um sociodrama ou psicodrama também pode ser percebido pela entonação de voz, pela pressão do toque no diretor, pelos ruídos de sua movimentação por vezes involuntária e por tantos outros sinais que evidenciam o momento do grupo ou indivíduo. Ou seja, não necessariamente uma pessoa com deficiência visual precisa de descrições de imagens, mas sim da sensibilidade e tele para com o grupo ou sujeito com o qual desenvolve um trabalho.

Além disso, cabem aqui os conceitos de iniciadores, definidos como "estímulos que podem desencadear diferentes processos de aquecimento", podem ser estímulos internos ou externos, voluntários ou não, físicos ou mentais, utilizados para o aquecimento do protagonista. Esse conceito se faz importante na compreensão de um psicodramatista com deficiência visual, já que os iniciadores vão desencadear uma série de sensações, tanto no protagonista como no próprio diretor. Ou seja, os iniciadores irão formar e depois manter a realidade suplementar, independentemente do que esteja sendo visto - ou não -, algo que se comprova quando, em uma cena, o protagonista "vê" o seu contrapapel no ego-auxiliar que o representa (Perazzo, 2019).

Por outro lado, quando as descrições de imagens efetivamente ocorrem, trazem consigo percepções muito singulares, pois aquele que descreve o faz a

\footnotetext{
${ }^{3}$ A autora com deficiência visual se refere a Editora Ágora, responsável por grande parte das publicações de livros em psicodrama e que converteu muitos deles a edições digitais para compra e leitura desta através de leitores de tela.
} 
partir da sua subjetividade, carregando as descrições de simbolismos que podem se constituir em elementos terapêuticos. No Psicodrama não se constroem imagens, mas símbolos. Símbolos que representam os sentimentos, as relações, as percepções e os pensamentos. Dessa forma, não é o visualizar aquilo que mais importa, mas sim a tele com o grupo ou protagonista, porque o psicodrama possibilita uma intervenção que vai para muito além da realidade concreta. Cukier (2019) afirma que demonstrar nosso respeito a Moreno é também criar a partir do que ele deixou. Que possamos fazer isso também através de um psicodrama possível para todos, sem impor barreiras ou olhares "tortos" ao outro. Precisamos do reconhecimento do eu de muitos psicodramatistas cegos, mas isso se dá via tu, ou seja, através dos videntes que questionam a conserva cultural capacitista e permitem descobrir junto ao psicodramatista com deficiência visual caminhos que podem ou não se interseccionar.

\section{Considerações finais}

O psicodramatista é aquele que possibilita a verdade do protagonista ou grupo através da ação dramática, buscando respostas espontâneas e criativas. Na teoria moreniana, inclusão social é se relacionar télica e espontaneamente, de modo que todos sejam atores e autores de uma mesma história. Assim, não cabe pensar que o psicodrama possa se limitar a encarar um indivíduo a partir da deficiência que ele possui, mas sim perceber que essas só existem no contato com as barreiras sociais e que, com espontaneidade e criatividade, podemos contribuir para mitigá-las.

Nesse sentido, em relação à deficiência visual, é preciso desconstruir a conserva cultural de que o psicodrama é puramente imagético. Não é. O psicodrama é completamente simbólico, mesmo para aqueles que fazem uso da imagem para acessar esse simbolismo. Além disso, a compreensão de que os iniciadores de aquecimento auxiliam nesse processo elucida a ideia de que, juntos, diretor e protagonista conseguem atingir a realidade suplementar. Ao atingir essa compreensão, podemos então agir com espontaneidade e criar meios para que psicoterapeutas com deficiência visual - cegos ou com baixa visão - sintam-se impelidos a conhecer, vivenciar e aplicar o psicodrama na sua infinidade de métodos e técnicas.

Entendemos que este estudo é um primeiro passo para que possamos pensar na pessoa com deficiência como sujeito ativo no psicodrama, bem como nas demais psicoterapias. Compreendemos também que a análise de uma vivência subjetiva não fornece dados que possam ser replicados e utilizados por todo e qualquer Psicodramatista com deficiência visual. Buscamos, por meio dos métodos empregados e da escrita à várias mãos, mitigar vieses de análise do conteúdo apresentado. Esse, no entanto, foi muito mais um cuidado ético do que um objetivo do estudo. Nosso objetivo permeia a busca de representatividade nas psicoterapias, sobretudo em meio psicodramático, e, para isso, valorizar a experiência da autora como representante de uma categoria invisibilizada socialmente é um primeiro passo para que possamos considerar as pessoas com deficiência visual não apenas como quem participa, o sujeito passivo da habilitação e reabilitação, mas como quem cria e propõe novos fazeres. Assim sendo, percebemos que um estudo com a metodologia escolhida tem limitações em relação a um único ponto de perspectiva e, justamente por isso, consideramos importante o desenvolvimento de pesquisas que possam contemplar outras deficiências, bem como outros saberes/fazeres psicológicos.

\section{Contribuições dos autores}

\begin{abstract}
Oliveira DC participou da concepção, delineamento, busca e análise dos dados, interpretação dos resultados, redação do artigo científico. Vidal GP participou da concepção, delineamento, busca e análise dos dados, interpretação dos resultados, e redação do artigo científico. Castro A participou da concepção, delineamento, análise e interpretação dos resultados, redação e revisão
\end{abstract}

\section{Conflitos de interesses}

\footnotetext{
Nenhum conflito financeiro, legal ou político envolvendo terceiros (governo, empresas e fundações privadas, etc.) foi declarado para nenhum aspecto do trabalho submetido (incluindo, mas não se limitando a subvenções e financiamentos, participação em conselho consultivo, desenho de estudo, preparação de manuscrito, análise estatística, etc.).
} 


\section{Referências}

Amaral, L. C. (2019). Pessoa com deficiência: inclusão e acessibilidade na sociedade contemporânea. Legis Augustus, 12(1), 33-52. https://doi. org/10.15202/10.15202/2179-6637.2019.v12n1p33

Auad, J. C., \& Conceição, M. I. G. (2008). Inserção social universitária: uma investigação com base no átomo social mínimo. Paidéia (Ribeirão Preto), 18(39), 139-154. https:// doi.org/10.1590/S0103-863X2008000100013

Bisol, C. A., Pegorini, N. N., \& Valentini, C. B. (2017). Pensar a deficiência a partir dos modelos médico, social e póssocial. Cadernos de Pesquisa, 24(1), 87-100. http://dx.doi. org/10.18764/2178-2229.v24n1p87-100

Decreto n. 6.949, de 25 de agosto de 2009. Promulga a Convenção Internacional sobre os Direitos das Pessoas com Deficiência e seu Protocolo Facultativo, assinados em Nova York, em 30 de março de 2007. Recuperado de http://www.planalto.gov.br/ccivil 03/ ato2007-2010/2009/ decreto/d6949.htm

Bustos, D. (2020). O grito de Narciso. In M. C. Malaquias (Org.), Psicodrama e relações étnico-raciais (pp. 83-92). Ágora.

Carlomagno, M. C., \& Rocha, L. C. (2016). Como criar e classificar categorias para fazer análise de conteúdo: uma questão metodológica. Revista Eletrônica de Ciência Política, 7(1). http://dx.doi.org/10.5380/recp.v7i1.45771

Cukier, R. (2019). Psicodrama Bipessoal: sua técnica, seu terapeuta e seu paciente. Ágora. https://www.gruposummus.com.br/ livro/psicodrama-bipessoal/

Fonseca, J. (2018). Essência e personalidade: elementos de psicologia relacional. Ágora.

Martín, E. G. (2019). Psicologia do encontro: J. L. Moreno. Ágora.

Marques, V., \& Satriano, C. (2017). Narrativa autobiográfica do próprio pesquisador como fonte e ferramenta de pesquisa. Linhas Críticas, 23(51), 369-386. https:// periodicos.unb.br/index.php/linhascriticas/article/ view/8231/6742

Mello, A. G. (2016). Deficiência, incapacidade e vulnerabilidade: do capacitismo ou a preeminência capacitista e biomédica do Comitê de Ética em Pesquisa da UFSC. Ciência \& Saúde Coletiva, 21(10), 3265-3276. https://doi.org/10.1590/1413$\underline{812320152110.07792016}$
Menegazzo, C. M., Tomasini, M. A., \& Zureti, M. M. (2019). Dicionário de Psicodrama e Sociodrama. Ágora.

Merengué, D. (2009). Corpos tatuados, relações voláteis: sentidos contemporâneos para o conceito de conserva cultural. Rev. Bras. de Psicodrama, 17(1), 105-114.

Monteiro, G. B. M. (2005). Concepções e uso de auxílios ópticos por escolares com deficiência visual. [Dissertação mestrado, Universidade Estadual de Campinas]. Repositório da produção cientifica e intelectual da Unicamp. http:// repositorio.unicamp.br/jspui/handle/REPOSIP/311245

Moreno, J. L. (2016). Psicodrama. Editora Pensamento/Cultrix.

Moreno, Z. T., Blomkvist, L. D., \& Rutzel, T. (2001). A Realidade Suplementar e a Arte de Curar. Ágora.

Nery, M. P. (2020). Sobre o silêncio estrondoso e o grito silenciado. In A. M. Dedomenico \& D. Merengué (Orgs.). Por uma vida espontânea e criadora: psicodrama e política (pp. 107-124). Ágora.

Nóbrega, D. O. (2017). Representações sociais de psicólogo: imagens em movimento na formação profissional. [Tese de doutorado, Universidade Federal do Rio Grande do Norte]. Repositório Institucional UFRN. https://repositorio.ufrn.br/ handle/123456789/24368

Moises, R. R., \& Stockmann, D. (2020). A Pessoa com Deficiência no Curso da História: Aspectos Sociais, Culturais e Políticos. History of Education in Latin America-HistELA, 3(e20780), 1-17. https://periodicos.ufrn.br/histela/article/ view/20780/12873

Perazzo, S. (2019). Ainda e Sempre Psicodrama. Ágora.

Rojas-Bermúdez, J. G. (2016). Introdução ao psicodrama. Ágora.

Santos, W. (2016). Deficiência como restrição de participação social: desafios para avaliação a partir da Lei Brasileira de Inclusão. Ciência \& Saúde Coletiva, 21(10), 3007-3015. https://dx.doi.org/10.1590/1413-812320152110.15262016

Silveira, F. T. (2019). A pesquisa autobiográfica e o corpo na formação da professora e do professor de Teatro. In A. K. Zanella \& M. V. Peres. Memórias do corpo biográfico: Como elas habitam em nós? (pp. 51-55). Oikos.

Souza, F. C. S., \& Aliança, P. T. S. S. M. (2018). Da ilusão à sedução: a crise do paradigma dominante e a emergência da pesquisa (auto) biográfica. CONJECTURA: filosofia e educação, 23(3), 561-578. https://dx.doi. org/10.18226/21784612.V23.N3.7 